\title{
Husserlian Phenomenology, Rule-following, and Primitive Normativity
}

\author{
Jacob Rump
}

Forthcoming in Language and Phenomenology (Routledge; ed. Chad Engelland)

Please cite only from the published version.

ABSTRACT: This paper presents a phenomenological approach to recent debates in the philosophy of language about rule-following and the normativity of meaning, a debate that can be traced to Ludwig Wittgenstein's Philosophical Investigations but that was given new life with Saul Kripke's Wittgenstein on Rules and Private Language. Taking a cue from Hannah Ginsborg's recent work on "primitive normativity," I use some of Husserl's own comments about meaning and the status of rules to sketch a solution to Kripke's rule-following paradox by appealing to a kind of normativity at the level of perception and intersubjective embodiment. This level of normativity arises, like Ginsborg's, via a primitive kind of judgment that does not presuppose linguistic or conceptual mastery. Unlike for Ginsborg, however, for Husserl this level should still be understood in terms of meaning - just not in the standard linguistic or conceptual senses prominent in the Anglo-American philosophical tradition in which the rule-following debates have occurred. My interpretation thus also demonstrates how Husserl's account bypasses certain presuppositions about meaning common in the period of the linguistic turnpresuppositions also questioned, in different ways, by Wittgenstein, by Kripke, and by Ginsborg.

KEYWORDS: Normativity, Husserl, Wittgenstein, Rule-following, Intentionality, Meaning Embodiment, Intersubjectivity

This paper outlines a Husserlian phenomenological approach to debates in the philosophy of language about rule-following and the normativity of meaning, following some of Husserl's own remarks about meaning and the status of rules. While Edmund Husserl's phenomenology predates Ludwig Wittgenstein's introduction of these issues in the late 1930s and 1940s as well as Saul Kripke's influential re-introduction of them in the 1980s, Husserl was interested in many of the same broad issues, especially concerning the objectivity and intersubjectivity of meaning vis-à-vis normativity. Sketching a Husserlian solution to the rule-following paradox will not only 
provide an occasion to interpret his phenomenological approach to these issues; it will also allow me to show how this approach bypasses certain presuppositions about meaning common in the period of the linguistic turn — presuppositions also questioned, in different ways, by Wittgenstein himself, by Kripke, and more recently by Hannah Ginsborg.

In Section I, I introduce Kripke's formulation of the rule-following paradox and identify some concepts that will need to be addressed in any phenomenological solution to it: dispositionalist arguments for reductionism about meaning; anti-reductionism about meaning; and the normativity of meaning. Section II examines Ginsborg's recent approach, which seeks a middle way between full reductionism and anti-reductionism about meaning while holding on to the notion that meaning is grounded in "primitive normativity." I go on in Section III to show how Husserlian phenomenology is grounded in a different version of primitive normativity, one that maintains a direct connection between primitive normativity and meaning at the level not of language but of intentionality, exhibited in perception itself. On this view perception is understood not simply as a mode of access to facts guaranteeing objectivity, but as the continued, lived unfolding of experience that points beyond those facts to broader intentional horizons of possible meaning. Section IV demonstrates how this account, like Ginsborg's, relies on the notion of a more primitive level of judgment but locates such judgment in embodied practices, the normative grounding of which is ultimately for Husserl—as for Kripke and Wittgensteinnot individual but communal. Section V argues that this interpretation of Husserl amounts to what Kripke would call a "sceptical solution" to the rule-following paradox, in that it accepts the sceptical insight that meaning cannot be reduced to an account of facts; thus, while it resists reductionism about meaning, it also insists that this insight does not affect the status of meaning as characteristic of our everyday lives and experiences. The phenomenological solution is thus 
not really a middle way at all, but rather a different, more refined version of anti-reductionismone that takes meaning itself, though not exclusively in the guise of language or concepts- to be primitive.

\section{RULE-FOLLOWING, DISPOSITIONS, AND NORMATIVITY}

Interest in Wittgenstein's remarks on rule-following was renewed in Kripke's 1982 Wittgenstein on Rules and Private Language, wherein he introduces the idea of a particular sort of scepticism - "meaning scepticism"- that challenges our very conception of linguistic meaning. Following Wittgenstein, Kripke sketches a paradox using an arithmetical example — though he emphasizes that the paradox applies to meaningful language use in general $(1982,7)$. The meaning in question is that of the term 'plus' or the sign '+,' either of which we can interpret as standing for the rule of addition. The notion of a rule is important here because it seems to capture the idea that the relevant meaning should apply to an indefinite and potentially infinite number of future cases $(1982,7-8)$. Only in this way can I see my current usage as conforming with my past usage, and thus be sure of what I meant.

Now, Kripke says, suppose I am faced with a new computational problem that I have never solved before: $68+57$. I solve the problem, arriving at the sum of 125 , confident that my answer is correct "both in the arithmetical sense that 125 is the sum of 68 and 57, and in the metalinguistic sense that 'plus', as I intended to use that word in the past, denoted a function which, when applied to the numbers I called '68' and '57', yields the value 125" $(1982,8)$. But then suppose, Kripke says, that I am faced with an objection from a "bizarre sceptic" not on the arithmetic but on the metalinguistic level:

Perhaps, he suggests, as I used the term 'plus' in the past, the answer I intended for ' $68+$ 57 ' should have been ' 5 '! . . If 1 am now so confident that, as I used the symbol '+ ', my 
intention was that ' $68+57$ ' should turn out to denote 125 , this cannot be because I explicitly gave myself instructions that 125 is the result of performing the addition in this particular instance. By hypothesis, I did no such thing. But of course the idea is that, in this new instance, I should apply the very same function or rule that I applied so many times in the past. But who is to say what function this was? In the past I gave myself only a finite number of examples instantiating this function. All, we have supposed, involved numbers smaller than 57. So perhaps in the past I used 'plus' and ' + ' to denote a function which I will call 'quus' and symbolize by '[quus symbol]'. It is defined by:

$\mathrm{x}$ [quus] $\mathrm{y}=\mathrm{x}+\mathrm{y}$, if $\mathrm{x}, \mathrm{y}<57$

$=5$ otherwise. $(1982,8-9)$

What fact can I, the speaker, appeal to, in order to prove that I previously meant "plus" and not "quus"- that the intention behind my previous usage was addition, and not "quaddition?" This amounts not simply to the epistemological question about how I know that I meant "plus" and not "quus," but also to the metaphysical question in virtue of what is it the case that I meant "plus" and not "quus?" $(1982,39)$. The point of the sceptical paradox is not simply to throw doubt on my introspective certainty concerning my own intentions as a speaker, but rather to throw doubt on the whole notion of meaning: if there is no fact of the matter determinant of our meaning- intentions, then how does anyone ever mean anything at all?

The relevance of the notion of rule-following for giving an account of meaning is evident in the fact that — put very generally—we take meaning to be a phenomenon governed by objective parameters not exclusively in the control of the speaker. Unless constraints of some sort are determined for it in advance, it seems, my meaning-intentions could amount to anything at all: there would be no objectivity constraint external to my individual thinking - no fact of the matter - which determines what I intended to mean in using a word, and thus, in the addition case, there is nothing to which I can appeal to prove that I in fact meant "plus" instead of "quus." In order for there to be such an objective predetermination, it seems we need in some way to reduce my meaning in uttering a word or a sentence to something not of the same order as that meaning, on pain of regress: it cannot be the case that the rule-following that is determinant of Rump, Husserlian Phenomenology, Rule-following, and Primitive Normativity 4 
the meaning of a given pattern of linguistic usage itself results from following an antecedent (linguistic) rule - a rule for following a rule - for then the antecedent rule would itself be a rule the following of which could only be explained by a further antecedent one, and so on. At some point, in order to avoid the regress, it must be possible to reduce linguistic meaning to something outside the linguistic domain altogether.

At first glance, it might seem plausible to accomplish this by reduction from language to the domain of concepts as the vehicle of mental content underlying and giving meaning to linguistic expressions. However, this only pushes the problem back: we will now need to find the rules for correct concept application in terms of antecedent conceptual rules. As Paul Boghossian has noted, the sceptical arguments Kripke advances call into question not only linguistic meaning, but also meaning as a function of concepts or a language of thought, and thus seem to call into question the notion of mental content as such $(1989,510-14)$.

The most obvious remaining candidate for reductionism about meaning is some sort of fact about my dispositions. Kripke sums up the dispositionalist response to the paradox thus:

True, my actual thoughts and responses in the past do not differentiate between the plus and the quus hypotheses; but, even in the past, there were dispositional facts about me that did make such a differentiation. To say that in fact I meant plus in the past is to sayas surely was the case! - that had I been queried about ' $68+57$ ', I would have answered '125'. By hypothesis I was not in fact asked, but the disposition was present none the less. $(1982,23)$

While Kripke advances several arguments against such dispositionalism, the most important for our purposes is the claim that any attempt to account for my past meaning in terms of dispositional facts about my past states will ultimately run up against the normativity of meaning: At most, dispositional facts could explain what a given human being will mean in future uses of a word. But our meaningful usage of language is premised upon an understanding of meaning not as a function of what a speaker will in fact mean, in future utterances, but of what they should 
mean in those utterances. To see this, we need only consider Kripke's examples of ways in which the speaker's intention could go wrong (e.g., in the arithmetic example): “computational error, finiteness of my capacity, and other disturbing factors may lead me to be disposed not to respond as I should, but if so, I have not acted in accord with my intentions." It is the normativity governing these intentions for future usage, not the fact(s) about my dispositions, that must ultimately ground my response in the sense of making it meaningful, and thus "the relation of meaning and intention to future action is normative, not descriptive" $(1982,37)$.

In light of this normativity constraint, Kripke's sceptic challenges dispositionalist positions (and reductionist positions more broadly) by questioning the existence of any fact determinant of meaning-intentions (Kripke 1982, 28). The "sceptical solution" Kripke attributes to Wittgenstein is anti-reductionist (or non-reductionist; I take the terms to be interchangeable) in that it accepts that there is no such fact. But it also insists that this solution leaves untouched the conviction of our everyday experience, "that when people speak of themselves and others as meaning something by their words, as following rules, they do so with perfect right" $(1982,69)$. I argue below that this conviction - that in spite of the skeptical paradox, meaning is always already evident in our experience — is essential for any phenomenological approach to the issue of rule-following.

One of the great difficulties raised by the rule-following paradox is that this normativity constraint is in tension with the objectivity constraint discussed above. The reductionist will claim that, in its zeal to give credence to the normativity of meaning, anti-reductionism risks downplaying the very aspect of meaning that makes it seem intuitively akin to rule-following to begin with. The whole point of thinking about meaning in terms of rules is to explain the way in which language can be shared and used objectively and thus publicly, and the anti-reductionist 
move does not adequately ground the sort of objectivity that the ability for linguistic communication entails insofar as it fails to escape the picture of meaning as consisting exclusively of the subjective intentions of the speaker - precisely the problem that first raised the paradox and left us unable to identify our language use with "plus" instead of "quus." Put differently, even if meaning is in some sense normative, what I should mean by a word cannot simply be a matter of whatever I subjectively feel like meaning; meaning must meet the objectivity constraint by being somehow governed by rules that pertain to something outside the will or whims of the subject. We can summarize this discussion in the following table:

\begin{tabular}{|l|l|l|}
\hline \multicolumn{1}{|c|}{ View of Meaning } & \multicolumn{1}{|c|}{ Constraints Met (and how met) } & \multicolumn{1}{|c|}{ Foundational Level } \\
\hline $\begin{array}{l}\text { reductionism } \\
\text { (dispositionalism) }\end{array}$ & $\begin{array}{l}\text { objectivity (dispositional facts as inherently objective) } \\
\text { problem: fails to meet normativity constraint }\end{array}$ & facts \\
\hline $\begin{array}{l}\text { standard } \\
\text { anti-reductionism }\end{array}$ & $\begin{array}{l}\text { normativity (meaning as inherently normative) } \\
\text { problem: fails to meet objectivity constraint }\end{array}$ & $\begin{array}{l}\text { meaning (meaning = linguistic, } \\
\text { conceptual) }\end{array}$ \\
\hline
\end{tabular}

\section{GINSBORG ON PRIMITIVE NORMATIVITY}

Given these parameters, one obvious strategy for dealing with the rule-following paradox is to attempt to do justice to both the objectivity constraint and the normativity constraint through some sort of "middle way" between the extremes of reductionism and anti-reductionism. In recent work, Hannah Ginsborg attempts such a middle way by appeal to the notion of primitive normativity. In an important passage in her well-known 2011 essay on the topic, she extends familiar discussions of rule-following via examples of the use of arithmetical language to an example of the acquisition of color concepts. We are asked to imagine a child without mastery of color concepts, who, following the example of an adult who does have such mastery, successfully sorts out all the green members of a set of objects of various sizes and shapes, despite her lack of mastery of the word "green" or the concept green. Despite this lack of 
mastery, Ginsborg claims, the child's successful completion of the sorting procedure is normative in the sense that it amounts to a kind of judging: "it is plausible that she does so with a sense that this is the appropriate thing to do. She takes it that the green spoon 'belongs' in the box containing the previously sorted green things and that the blue spoon does not" (2011b, 235).

Unlike a trained parrot, who may have a similar disposition to respond with "green," the child in the block-sorting example "takes herself to be responding appropriately" — she has "consciousness of appropriateness," and thus, contra the parrot, the child "does not respond 'blindly' to her circumstances." She sees her utterance as appropriate (2011b, 237). Ginsborg leverages the normative status of this "taking-to-be-appropriate" to claim that her account of primitive normativity is still "nonreductionist to the extent that it requires us to accept at least one sui generis intentional attitude, namely, the attitude through which we take each of our actual responses to be appropriate to the circumstances" $(2011 \mathrm{~b}, 252)$. Primitive normativity is thus only disposition-like; it does not fully collapse into reductionism and thus remains capable of meeting the normativity constraint.

At the same time, since this taking-as-appropriate is a precondition for linguistic or conceptual mastery, it cannot presuppose such mastery, and, ipso facto, taking-to-be-appropriate does not depend on the child "taking what she is doing to accord with a rule that she was following, for example, the rule that she is to put all of the green things in the same box" (2011b, 235). Since it does not depend on the self-conscious entertaining of rules in the form of the linguistic or conceptual contents of her mental states, this primitive level of taking to be appropriate can still be explained in a quasi-reductive manner as the "actualization" of a disposition $(2011 b, 244)$. And because of this, Ginsborg claims for her account "the advantage 
over traditional anti-reductionism that it is able to accommodate the quasi-dispositional character of meaning and rules, and so to tie meaning to our actual patterns of response" $(2011 \mathrm{~b}, 252)$. Without some form of reduction of meaning to at least this "quasi-dispositional" level, we would fail "to account for the way in which what someone means, or what rule she is following, seems to determine not just what she ought to do, but what she in fact will do" (2011b, 230), and thus, too, we would fail to meet the objectivity constraint. Through the combination of taking-to-beappropriate and quasi-dispositionalism, then, Ginsborg's notion of primitive normativity amounts to a "middle way" between reductionism and anti-reductionism.

From a Husserlian phenomenological perspective, Ginsborg's move to locate normativity directly in primitive judgments about our lived experience get things exactly right. Indeed, it places her position in a philosophical tradition beyond and antedating phenomenology: to translate Ginsborg's claims above into a slightly different vocabulary_one warranted by her own attribution of this view to Kant's third Critique - this level of judgment in primitive normativity is transcendental, both in the sense that it counts as condition for the possibility of meaning as understood at the level of language and concepts, and in the sense that it is based in the epistemological recognition that meaning and knowledge issue from the subject.

Because of this recognition of the ineliminable role of subjectivity in meaning, Ginsborg insists that this primitive level of judgment should not be construed as a judging of facts; it is "not in the first instance to be identified with the acceptance of some proposition as true" (2011a, 177). When one uses a term as it ought to be used, she writes,

The "ought" is not that of practical rationality, nor can it be understood as the kind of 'semantic correctness' which can be explicated in terms of truth. Rather, it is what I have called a primitive "ought," whose recognition does not depend on an antecedent grasp of meanings and concepts but which instead makes it possible for sounds and marks . . . to amount to meaningful discourse in the first place. Such an "ought." I have suggested 
elsewhere, informs our most basic sorting inclinations, or what we might call our "ways of going on" from initial samples. (Ginsborg 2012, 137, my emphasis)

This prioritizing of questions about meaning over questions about truth can be seen as a further transcendental aspect of Ginsborg's view. On the transcendental but also phenomenological view I sketch below, Ginsborg is right that this primitive "ought" isn't dependent on an antecedent grasp of linguistic meanings, and that such primitive normativity makes it possible for sounds and marks to amount to meaningful discourse.

But the passage above suggests that Ginsborg takes the primitive level below linguistic and conceptual meaning to be thereby below the level of meaning tout court. In the same essay, in defending her view against a certain line of dispositionalist response, she notes that her view implies the "further requirement that this normative attitude be understood as somehow constitutive of, and thus in a strong sense antecedently presupposed by, the possibility of meaning" (2012, 139-140). Ginsborg does not directly address the question of whether there might be some domain of meaning outside of the linguistic or conceptual, but her characterization of primitive normativity as "quasi-dispositional" (and thus a kind of partial reductionism) strongly speaks against it. While Ginsborg has met the normativity constraint, she does so in a way that still reduces meaning in the sense that it appeals to a level more foundational than meaning. In this sense, her notion of primitive normativity hews too close to reductionism to count as a genuine "middle way."1 Thus we can expand our table from above:

\begin{tabular}{|l|l|l|}
\hline \multicolumn{1}{|c|}{ View of Meaning } & \multicolumn{1}{|c|}{ Constraints Met (and how met) } & \multicolumn{1}{c|}{ Foundational Level } \\
\hline $\begin{array}{l}\text { reductionism } \\
\text { (dispositionalism) }\end{array}$ & $\begin{array}{l}\text { objectivity (dispositional facts as inherently objective) } \\
\text { problem: fails to meet normativity constraint }\end{array}$ & facts \\
\hline $\begin{array}{l}\text { Ginsborg's } \\
\text { partial reductionism } \\
\text { (quasi-dispositionalism) }\end{array}$ & $\begin{array}{l}\text { objectivity (taking to be appropriate as actualization of a disposition); } \\
\text { normativity (taking to be appropriate as primitive ought) } \\
\text { problem: meets normativity constraint outside domain of meaning }\end{array}$ & $\begin{array}{l}\text { primitive normativity as prior to } \\
\text { meaning (meaning = linguistic, } \\
\text { conceptual) }\end{array}$ \\
\hline
\end{tabular}

\footnotetext{
${ }^{1}$ For a related critique of Ginsborg’s “partial reductionism,” see Miller 2019. Rump, Husserlian Phenomenology, Rule-following, and Primitive Normativity 10
} 


\section{PERCEPTION AS INTENTIONAL MEANING}

In the first section of this paper I pointed out the need, in order to meet the objectivity constraint, to reduce linguistic meaning to something outside of and — pace Ginsborg, more primitive than-language and concepts. But fulfilling this requirement need not equate to a reduction to something outside of meaning tout court. The Anglo-American philosophical tradition in which the debates about rule-following developed has tended to assume, in line with its historical roots in the linguistic turn, that questions of meaning are ultimately questions about language and concepts. Ginsborg, despite the novelty and Kantian background of her account of primitive normativity, remains thoroughly in the Anglo-American tradition in this respect. The Husserlian phenomenological position I am sketching insists, instead, that what we are talking about at the level of primitive normativity must itself count as meaningful. On this view, primitive normativity is indeed, as Ginsborg insists, a pre-condition for linguistic and conceptual meaning, but not, as for her, in virtue of the "quasi-disposition" of taking-to-be appropriate. Rather, takingto-be appropriate is itself only comprehensible against the prior background of the world as meaningful. The child is able to see her action (sorting, counting) as appropriate only because she can, even more fundamentally, see-as (take-as) at all. This seeing-as is characteristic of the basic structure of intentionality, and on a Husserlian view it is via this primary and essential structure of experience — not in some external fact—-that the objectivity constraint is met.

As the phenomenon of seeing-as suggests, the place to look for a meaningful level of primitive normativity in Husserl is not directly to his account of linguistic meaning, but to his 
account of perceptual meaning [Wahrnehmungssinn]. ${ }^{2}$ Husserl describes the structure of perceptual meaning as the "model" of the sort of lawfulness that governs consciousness (1966, 320). To say that perception is lawful or rule-governed, for Husserl, is to connect subjectivity to the domain of objectivity via the structure of intentionality: perception is of the real world, and that world is inherently meaningful, in a way not simply determined by my thoughts about it. Indeed, this is one way of understanding Husserl's famed "phenomenological reduction," which is, in a sense, the very antithesis of the attempt to reduce meanings to facts as discussed above: when Husserl insists that we "bracket" all existential commitments and metaphysical presuppositions in order to focus on the contents of conscious experience as such, he is in effect insisting that we analyze the world as first and foremost a world of meaning, regardless of the status of the meaning-objects that are given as existing in the realm of empirical fact (e.g., tables and chairs), not existing (e.g., unicorns), or existing (subsisting) ideally (e.g., mathematical objects and functions, including addition ${ }^{3}$ ) (see Husserl 1999, esp. Lecture V). Meaning arises in intentionality - the "aboutness" of consciousness or the correlation between the mind's intending (in Husserl's technical terminology, "noesis") and the meaning-object intended ("noema")—and is characterized normatively in terms of success ("fulfillment") or failure

\footnotetext{
${ }^{2}$ We see the turn to perceptual meaning already in Husserl's early work after his transcendental turn, in the period in which his relationship to transcendental idealism (and to Kant) becomes explicit, and arguably even more strongly in the period of his later "genetic" phenomenology. In this short essay I have focused broadly on Husserl's transcendental phenomenology across these periods, thus some ignoring important interpretive nuances that arise due to gradual revisions in his position.

${ }^{3}$ Husserl was trained as a mathematician, and his phenomenology is Platonic insofar as it interprets all meanings ultimately in terms of essences. This might appear to be in tension with my emphasis below on intentional meaning in perception as typical rather than conceptual and "determinably indeterminate" rather than exhaustively predetermined. But what I provide below is an analysis of meaning- objects as intentional objects for a subject, not of meanings qua essences sub specie eternitatis, of which the meaning of the function of addition (as opposed to my meaning in using the word "plus") would be one example. Kripke relies on a similar distinction in his characterization (cited above) of the sceptic's objection as not arithmetic, but metalinguistic. The tension between the eidetic and genetic-historical aspects of Husserl's method is an important problem for phenomenologists is and closely related to the issues discussed here, but exceeds my scope in this essay.
} 
("frustration") of intentions. ${ }^{4}$ But Husserl's phenomenological reduction is no retreat into a solipsistic idealism: I neither get to determine whether my intentions successfully meet the conditions (thinking of myself as a millionaire does not, alas, fulfill the thought and make me one), nor to determine what the meaning conditions are (I do not get to decide what makes one a millionaire any more than I get to decide what counts as addition). Meaning is in the world, not "in my head." Though it is not the only one, perception is the most paradigmatic mode of such intentionality - the place where we most obviously and directly encounter meaning in (in Husserl's terminology, in which we "constitute," which does not mean "create") the world. Thus the objectivity constraint is met via the primacy of intentionality as a structure that is both rulegoverned and subject to external parameters via fulfilment.

At the same time, Husserl insists - in what amounts to a rejection of reductionism about meaning - that we cannot exhaustively account for the meaningfulness of perceptual experience if we limit our conception of it to facts about the objects we perceive. Perception tells us not only what is the case, in our present intentions, but also what ought to be the case, in the form of implicit anticipations about our future experience. ${ }^{5}$ If I open a door to reveal only a brick wall directly behind it, my normal perceptual intentions have been frustrated rather than fulfilled. But this frustration is not simply the result of some dispositional fact about me or some empirical fact about the world; it is a frustration rooted in the way I already anticipate that the world should be — of my normal and typical ways of seeing-as. ${ }^{6}$ The account of intentionality also meets the normativity constraint via our anticipations about the meaningful world.

\footnotetext{
${ }^{4}$ See Crowell 2013 for a detailed phenomenological account of normativity in terms of conditions of success of failure.

${ }^{5}$ For a more detailed account of anticipations in Husserl, see Rump 2018.

${ }^{6}$ At first blush, Ginsborg's account - especially in her characterization of normativity in terms of a "primitive ought" and a "way of going on from initial samples" - is similar. But while she is concerned to do justice to the
} 
Intentional meaning is neither reducible to empirical facts nor limited to the linguistic or the conceptual. Take the following description of lawfulness and rule-following in perception from Husserl's 1917 inaugural lecture in Freiburg:

The pure phenomena through which a possible spatial Object presents itself to consciousness have their a priori definite system of necessary formations which is unconditionally binding upon every cognizing consciousness if that consciousness is to be able to intuit spatial reality. Thus, the ideal of a spatial thing prescribes a priori to possible consciousness of such a thing a set rule, a rule that can be followed intuitively and that admits of being conceived, in accord with the typicality of phenomenal forms, in pure concepts. And the same is true of every principal category of objectivities. The expression 'a priori' is therefore not a cloak to cover over some ideological extravagance but, is just as significant as is the 'purity' of mathematical analysis or geometry. (2002, 132)

Husserl notes both that the rule-governedness of perception can be "conceived" in terms of concepts and that it is followed "intuitively." This again parallels Ginsborg's account: though the child sorting colored objects may be able to correctly describe her taking-as-appropriate in conceptual terms, that taking-as-appropriate $i t s e l f$ is not a matter of concepts. The notion of the concept is instead said to arise in accord with the "typicality of phenomenal forms," which are transcendentally prior, or, in Ginsborg's terms, more primitive.

The primary unit of meaning at this primitive level, according to Husserl, is not the content of a language or thought or the concept (conceptuality), but the type (typicality). When Husserl says that types are "presumed in the certainty of belief" $(1973, \S 7)$ or that the lifeworld "holds to its essentially lawful set of types, to which all life, and thus all science, of which it is the 'ground,' remain bound" $(1970,173)$, he is insisting that intentional analysis reveals

normativity constraint, and thus to reject a fully dispositionalist account that would "attempt a reduction of meaning to facts conceived purely naturalistically," her insistence that the resultant account is not fully anti-reductionist, but only "partly reductionist," relies on a reduction to "facts that are in a sense more primitive" than meaning (2011b, p. 230, my emphasis). In order to meet Kripke's challenge of whether (and how) it is a fact that I mean plus (Kripke 1982, p. 11; Ginsborg 2011b, p. 231), Ginsborg construes the disposition + normative taking-to-be-appropriate package as itself a fact. In this sense, her account can be seen to offer a "straight solution" to Kripke's sceptical paradox, whereas the Husserlian position I am outline amounts to a "skeptical solution," as explained below. 
perception to be already normatively governed in its anticipations, and - insofar as these are

“essentially lawful," tied to a rule.

But the notion of a rule must be understood phenomenologically, in terms of intentional

objects (noemata), rather than naturalistically, in terms of empirical facts about physical things:

What now does this talk of rule or law mean phenomenologically? What follows from determining that the inadequately given region of the "thing" prescribes rules for the course of possible intuitions (which obviously means the same as possible perceptions)? To this, the answer is: the essence of such a noema of the thing inherently contains, in an absolutely discernible manner, ideal possibilities of an "unlimited progression" of coherent intuitions, and, to be sure, [it contains] them in accordance with directions that are prefigured in typically determined ways (thus, too, parallel kinds of unlimitedness in the continuous series of corresponding noeses). (Husserl 2014, 297-98, my emphasis)

The thing, understood in the "natural attitude" as a material object to be studied by empirical science, is always only inadequately given in perception: I cannot, e.g., see all sides of it at once. But understood phenomenologically, as the meaning- object correlated with an intending noesis, the thing qua noema — qua meaning- object — is normative insofar as it essentially contains ideal possibilities—not empirical facts about what is the case. ${ }^{7}$

But while the way in which these possibilities are discovered is said to be "absolutely discernible," the possibilities as such are only "typically determined": unlike for dispositional accounts of rule-following, based on the presumption that objectivity can only be reached by reduction to facts, on this view there is no point even in principle at which we could reduce meaning to an exhaustive list of future possibilities contained in "the facts" of present

\footnotetext{
${ }^{7}$ My claims here and below rely on what has come to be called the "east coast" interpretation of Husserl's noema as the object intended as seen in the phenomenological attitude, as against the "west coast" interpretation of the noema as a distinct entity mediating between the intention and the object intended in a manner akin to Fregean Sinn. For an extensive defense of the former position, see Drummond 1990.
}

Rump, Husserlian Phenomenology, Rule-following, and Primitive Normativity 15 
experience, any more than we could, for Ginsborg, in analyzing the child's "“ways of going on” from initial samples" in the sorting of colored objects. ${ }^{8}$

\section{PRIMITIVE JUDGMENTS, THE LIFEWORD, AND EMBODIED}

\section{INTERSUBJECTIVITY}

This account of the partial pre-determination of meaning via types also shows that Husserl's account contains an analogue of Ginsborg's Kant-inspired transcendental appeal to primitive judgments as discussed in Section II. With the phrase “"unlimited progression” of coherent intuitions" in the passage above, Husserl is explicitly echoing Kant: there is always the a priori possibility of the subsumption of additional cases under a given concept which are not analytically contained within the concept (Kant 1998, A 25). The possibility in agreement here is rule-governed - in the sense of rules as "typically determined ways" of perceiving as discussed above-but not concept-governed. Although Kant's view is that if something is a concept, then it is a rule for the understanding, on the Husserlian view I am sketching here, this is not a biconditional: it does not imply the further claims that all rules governing the understanding are concepts, or that that all rule-governed judgment is conceptual judgment.

These latter, further claims are precisely those which Ginsborg criticizes in claiming that her notion of primitive normativity stems from a conception of judgment attributable to Kant in the third Critique..$^{9}$ In contrast to the Critique of Pure Reason, where judgment is allied with the faculty of understanding and thus explicitly tied to the use of concepts, in the Critique of the Power of Judgement, Kant "introduces the idea that judgment can function independently of the

\footnotetext{
${ }^{8}$ Ginsborg's analysis recalls Wittgenstein's discussion of samples in 2009, $\S \S 73-74$. Though I cannot address this here, Wittgenstein's discussion bears an important resemblance to Husserl's account of types as discussed above. ${ }^{9}$ Ginsborg 2006 discusses the Kantian connection in greater detail. 
understanding in situations where the relevant rules or concepts are not already specified ... not already in the understanding but rather made possible by those acts of judging themselves" (Ginsborg 2011b, 253). Acts of judgment may be more primitive than concepts, and indeed in some instances make them possible.

Husserl's account of perceptual meaning is tied to a similar, broadly normative notion of primitive, non-conceptual judgment, but conceived it in the manner sketched in the previous section - in terms of rules that are only partially predetermined:

If the sense of a thing is determined by the instances of givenness of the perception of it (and what else could determine the sense?), then it demands such imperfection, and necessarily refers us to continuously unified connections of possible perceptions that extend from any implemented perception in infinitely many directions in a systematically and firmly rule-governed manner, and, to be sure, in each direction without end, constantly dominated by a unity of sense. A horizon of determinable indeterminacy always remains in principle, regardless of how much progress we make experientially, regardless of how large the continua of current perceptions of the same thing that we have run through are. (Husserl 2014, 78, my emphasis)

In effect, the special function of judgment outside the purview of full determination by preexisting concepts, which Kant reserves for separate treatment in the third Critique, is already in play for Husserl in the straightforward epistemological analysis of perception of everyday physical objects. All experiences of perceptual meaning are characterized by such "determinable indeterminacy," in precisely the sense in which perceptions can be said to normatively follow a rule, but a rule that is, in Ginsborg's words, "not already in the understanding but rather made possible by those acts of judging themselves."

But what, more precisely, do such "acts of judgment themselves" amount to, outside the domain of language and concepts and thus, presumably, outside the domain of judgment conceived as predication? In his later work, Husserl argues that the primitive level of intentionality exhibited in perception, on the basis of which judgments at the higher level of 
predication are made, is still an "act of judgment in a broader sense" $(1973,61)$. The most primitive level of judgment is that exhibited in perceptual experience itself, "in the passage from aesthesis, from simple sensuous awareness, to acting, evaluating, and so forth" $(1973,64)$.

This shift from simple awareness to evaluation can be understood as the shift from seeing to seeing-as, discussed above. But Husserl also characterizes this primitive level of judgment in terms of acting - as a shift from aesthesis to kinaesthesis. The analysis of the normativity of perception as involving kinaesthesis is especially prevalent in Husserl's well-known analyses of the lifeworld in the Crisis, where he suggests that the horizons of "determinable indeterminacy" discussed above are ultimately traceable to the movements and practical activities of the lived body $(1970, \S 47)$. The possibilities for what can be presented to me in perceptual experience are partially determined by my own implicit sense of available bodily activity — of what I can $d o$ :

If I ask what is implied in the fact that the thing-exhibitings belong to the altering kinaestheses, I recognize that a hidden intentional 'if-then' relation is at work here: the exhibitings must occur in a certain systematic order; it is in this way that they are indicated in advance, in expectation, in the course of a harmonious perception. The actual kinestheses here lie within the system of kinesthetic capacity, which is correlated with the system of possible following events harmoniously belonging to it. This is, then, the intentional background of every straightforward ontic certainty of a presented thing. (Husserl 1970, 161f)

That "harmonious perception" should here be interpreted as "normatively governed perception" is clear from the claim, later in the passage, that in experience of the breakdown of such harmony, "the change of apperceptive sense takes place through a change of the expectationhorizon of the multiplicities anticipated as normal (i.e., as running on harmoniously)" (1970, 162). In such cases, it is not that I am suddenly perceiving a different physical object than I thought was, but rather that that object has frustrated my (often implicit, or, in Husserl's terminology, "non-thematic") normative anticipations with regard to its place in a nexus of possible meanings. It becomes a "different" object qua meaning-object: I now associate new 
meanings, and thus a new horizon of future (again largely non-thematic) meaning-possibilities, with it, and this shift both arises from and is registered in my system of bodily comportment, even when it does not rise to the level of thematic awareness as expressed in language or concepts.

But it is also clear from Husserl's later work that these normative, primitive judgments at the level of perception need not be limited to my judgments. The move to locate normativity in perception and, ultimately, in kinaestheses, also opens the way for an appeal beyond the individual embodied subject to an intersubjective, embodied community (De los Reyes Melero 2013). Kripke's own "skeptical solution" to the rule-following paradox ultimately requires us to "widen our gaze from consideration of the rule-follower alone and allow ourselves to consider him as interacting with a wider community" $(1982,89)$, and it should not be forgotten that the broader context of Kripke's book is a consideration of Wittgenstein's views on private language. Husserl's own accounts of the phenomenological reduction underwent a similar widening, from earlier presentations of a "Cartesian way" into the reduction, which appears to some commentators to veer dangerously close to solipsism, to later presentations of the reduction that emphasized the communal, intersubjective context of the lifeworld as the ultimate ground of meaningful experience (Cf. Luft, Introduction to Husserl 2019, lvii). Given what we have said above about a primitive level of judgment already in embodied perception, this determination by the wider community is not limited to the explicit (thematic) level of agreements and disagreements in our use of language and concepts; it occurs already, on Husserl's view, at the more primitive level of communal embodied activity (Carr 2019).

This account of communal, embodied determination is consistent with the picture we get from Ginsborg's example of the child sorting objects. Ginsborg claims that it is enough to 
ground normativity to say that the child is acting in a way that she takes to be appropriate. But the later Husserlian view — attuned to the primitive role of intersubjectivity and the lifeworldwould insist that, even prior to linguistic or conceptual mastery, the child does not simply take her response to be appropriate out of the blue. She does so only in the context of anticipations arising from what she has previously perceived to be appropriate actions, and this is nothing other than the "determinably indeterminate" context of bodily practices - both those she undertakes herself and those she sees in the context of her community - that she takes as meaningful. In taking her sorting activity to be an appropriate practice, the child has moved from aesthesis to kinaesthesis, from seeing to seeing-as, and this constitutes a primitive grounding of normativity even if no precise boundaries of appropriateness beyond the present case have been established.

Something very similar is suggested by Kripke when he reassures us, in the face of the skeptical paradox, that "in fact, our actual community is (roughly) uniform in its practices with respect to addition" (1982, 91, my emphasis). On the Husserlian account just offered, however, primitive normativity does not reduce — nor even, pace Ginsborg, "partially reduce"— to something more primitive than meaning. The re-casting of primitive normativity as an embodied and intersubjective phenomenon, alongside the phenomenological conviction that meaning does not bottom out at language or concepts, thus amounts to a fully anti-reductionist view of meaning. Thus we can add one more row to our table:

\begin{tabular}{|l|l|l|}
\hline \multicolumn{1}{|c|}{ View of Meaning } & \multicolumn{1}{|c|}{ Constraints Met (and how met) } & Foundational Level \\
\hline $\begin{array}{l}\text { reductionism } \\
\text { (dispositionalism) }\end{array}$ & $\begin{array}{l}\text { objectivity (dispositional facts as inherently objective) } \\
\text { problem: fails to meet normativity constraint }\end{array}$ & Facts \\
\hline $\begin{array}{l}\text { Ginsborg's } \\
\text { partial reductionism } \\
\text { (quasi-dispositionalism) }\end{array}$ & $\begin{array}{l}\text { objectivity (taking to be appropriate as actualization of a disposition); } \\
\text { normativity (taking to be appropriate as primitive ought) } \\
\text { problem: meets normativity constraint outside domain of meaning }\end{array}$ & $\begin{array}{l}\text { primitive normativity as prior to } \\
\text { meaning (meaning = linguistic, } \\
\text { conceptual) }\end{array}$ \\
\hline
\end{tabular}




\begin{tabular}{|l|l|l|}
\hline $\begin{array}{l}\text { Husserl's } \\
\text { anti-reductionism }\end{array}$ & $\begin{array}{l}\text { objectivity (intentionality as rule-governed structure of fulfilment) } \\
\text { normativity (intentionality as typically determined structure of anticipation) }\end{array}$ & $\begin{array}{l}\text { primitive normativity as } \\
\text { intentional meaning (meaning }= \\
\text { perceptual/ experiential) }\end{array}$ \\
\hline $\begin{array}{l}\text { standard } \\
\text { anti-reductionism }\end{array}$ & $\begin{array}{l}\text { normativity (meaning as inherently normative) } \\
\text { problem: fails to meet objectivity constraint }\end{array}$ & $\begin{array}{l}\text { meaning (meaning = linguistic, } \\
\text { conceptual) }\end{array}$ \\
\hline
\end{tabular}

\section{HUSSERL'S SCEPTICAL SOLUTION}

It may seem, at this point, that we have strayed quite far from the initial formulation of the rule-

following paradox, which was, after all, a paradox about the use of words or concepts-a

problem in the philosophy of language. But the fact that attention to the most primitive

manifestations of meaning has taken us not to conceptual or linguistic analysis but to an analysis

of the structures of experience is, in a way, precisely the point. While Husserl's theory of

meaning does include treatment of the philosophy of language, the considerations above show

that it takes the domain of meaning to extend more widely than the domain of the linguistic,

semantic, or conceptual. The phenomenological theory of meaning is thus misconceived if taken

as a sub-domain under the broader umbrella of the philosophy of language. For Husserl, the

theory of meaning is as much a matter of epistemology as of language. Indeed, both the

philosophy of language and epistemology can be said to fall under the broader domain of the theory of meaning.

The theory of meaning holds a similar priority over metaphysics for Husserl, as noted in Section III's discussion of "bracketing" in the phenomenological reduction. Take Kripke's insistence, noted in Section I, that responses to the rule-following paradox must answer not simply the epistemological question of how I know that I meant "plus" and not "quus," but also the metaphysical question of in virtue of what it is the case that I meant "plus" and not "quus." For Husserl—and here is yet another transcendental echo of Kant- these two questions are not neatly separable: the only way to make sense of the metaphysical question outside of or prior to 
the epistemological one would be to treat it as answerable via some appeal to the authority of empirical facts. But to do this would be to act under the very presupposition of the "natural attitude" that I have argued the phenomenological reduction rejects: the presupposition that the world consists primarily of empirical facts (and physical things) and only secondarily or derivatively of meaning.

The Husserlian view I have been sketching thus amounts to what Kripke calls a "sceptical solution" to the rule-following paradox, in that it accepts that there is no straightforward, fully determined fact of the matter about meaning in any single moment of my lived experience, thereby "conceding that the sceptic's negative assertions are unanswerable." As Kripke notes, instead of refuting the sceptic in the manner of a "straight solution," a "sceptical solution"-such as that in Hume's Enquiry - seeks to show how “our ordinary practice or belief is justified because - contrary appearances notwithstanding - it need not require the justification the sceptic has shown to be untenable." The untenable justification, in Husserl's case, is that which seeks to account for meaning by reducing it to facts. Kripke goes on to suggest that "much of the value of the sceptical argument consists precisely in the fact that he has shown that an ordinary practice, if it is to be defended at all, cannot be defended in a certain way" (1982, 66-67). For Husserl, I have argued, the "ordinary practice" of our taking our experience as normative and meaningful is itself primitive, and in this sense we might even say that it really needs no defense. At the very least, we cannot defend it in a manner that presupposes meaning to be an exclusively linguistic or conceptual affair.

But nor should we discount the importance of dealing with the paradox at the level linguistic meaning. With regard to Kripke's sceptic's scenario, then, how do I know that, in my previous linguistic usage, I meant “plus” and not "quus”? In a sense I don’t know-if knowing 
amounts to knowing some fact about myself or my context that would be conclusively determinative. To see this, we need only modify the passage about "determinable indeterminacy" cited above, transposing from the foundational level of intentional meaning to the higher level of linguistic meaning by replacing "perception" with "usage" and replacing "sense of a thing" with "meaning of an expression." 10 We get the following:

If the [meaning of an expression] is determined by the instances of givenness of the [usage] of it (and what else could determine the [meaning]?), then it demands such imperfection, and necessarily refers us to continuously unified connections of possible [usage] that extend from any implemented [usage] in infinitely many directions in a systematically and firmly rule-governed manner, and, to be sure, in each direction without end, constantly dominated by a unity of meaning. A horizon of determinable indeterminacy always remains in principle, regardless of how much progress we make experientially, regardless of how large the continua of current [usages] of the same [expression] that we have run through are. (Husserl 2014, 78, my emphasis and modifications)

In the terms of the Husserlian interpretation sketched above, I can really only say that my past usage of "plus" has been typical, and that I take my current usage to be consistent with the systematic and rule-governed horizon of possibilities determined by that past usage. But for Husserl, this is enough.

If the sceptic objects that this is not enough to meet the objectivity constraint, I can appeal to the way in which my linguistic usage is now and thus far has been roughly harmonious with both the expressions and also the broader context of embodied practices of myself and my community. At this point Husserl might well echo Wittgenstein: "It is not only agreement in definitions, but also (odd as it may sound) agreement in judgements that is required for communication by means of language" (Wittgenstein 2009, §242). Husserl would only insist on

\footnotetext{
${ }^{10}$ There is an important complication that I cannot address here concerning Husserl's distinction (which differs from Frege's) between sense [Sinn] and meaning [Bedeutung] in his middle and later work. For a recent account and references, see Rump 2018, §2. 
the primitive normativity and meaningfulness of those judgments already at the level of our lived experience, or, again with Wittgenstein, that "it is characteristic of our language that the foundation on which it grows consists in steady ways of living, regular ways of acting” (1993, 397). If such appeals do not convince the sceptic, it is not clear what sort of further evidence he is seeking, short of a reduction of meaning to facts. But such reductionism must pay the heavy price of violating the normativity constraint and flying in the face of the most primitive testimony of our lived experience: that the world we talk about is the world we always already live in-one that is constituted, first and foremost, not by language or concepts, nor by facts, but by meaning.

\section{REFERENCES}

Boghossian, P. (1989), “The Rule-Following Considerations,” Mind 98 (392): 507-549.

Carr, David (2019), "Intersubjectivity and Embodiment," in F. Kjosavik, C. Beyer, and C. Fricke (eds.), Husserl's Phenomenology of Intersubjectivity: Historical Interpretations and Contemporary Applications, New York: Routledge, 249-262.

Crowell, S. (2013), Normativity and Phenomenology in Husserl and Heidegger, Cambridge: Cambridge University Press.

De los Reyes Melero, I. (2013), "The Body as a System of Concordance and the Perceptual World," in R. T. Jensen and D. Moran (eds.), The Phenomenology of Embodied Intersubjectivity, Dordrecht: Springer, 105-120.

Drummond, J. (1990), Husserlian Intentionality and Non-Foundational Realism: Noema and Object, Dordrecht: Springer.

Ginsborg, H. (2006), “Aesthetic Judgment and Perceptual Normativity,” Inquiry 49 (5): 403437.

. (2011a), "Inside and Outside Language: Stroud's Nonreductionism about Meaning," in J. Bridges, N. Kolodny, and W. Wong (eds.), The Possibility of Philosophical Understanding: The Philosophy of Barry Stroud, Oxford: Oxford University Press, 14781. 
. (2011b), "Primitive Normativity and Scepticism about Rules," The Journal of Philosophy, 108 (5): 227-254.

. (2012), "Meaning, Understanding, and Normativity," Aristotelian Society Supplementary Volume 86 (1): 127-146.

Husserl, E. (1966), Analysen zur passiven Synthesis: Aus Vorlesungs- und

Forschungsmanuskripten 1918-1926, M. Fleischer (ed.), Den Haag: Marinus Nijhoff.

. (1970), The Crisis of European Sciences and Transcendental Phenomenology: An Introduction to Phenomenological Philosophy, D. Carr (trans.), Evanston: Northwestern University Press.

. (1973), Experience and Judgment: Investigations in a Genealogy of Logic, ed. L. Landgrebe, trans. J. S. Churchill and K. Ameriks, Evanston: Northwestern University Press.

. (1999). The Idea of Phenomenology, trans. L. Hardy, Dordrecht: Kluwer Academic Publishers.

. (2002), "Pure Phenomenology, Its Method, and Its Field of Investigation," in D. Moran and T. Mooney (eds.), The Phenomenology Reader, New York: Routledge, 124-133.

. (2014), Ideas for a Pure Phenomenology and Phenomenological Philosophy: First Book: General Introduction to Pure Phenomenology, trans. D. Dahlstrom, Indianapolis: Hackett.

. (2019), First Philosophy: Lectures 1923/24 and Related Texts from the Manuscripts (1920-1925), eds. S. Luft and T. Naberhaus, Dordrecht: Springer.

Kant, I. (1998), Critique of Pure Reason, eds. P. Guyer and A. W. Wood, Cambridge: Cambridge University Press.

Kripke, S. (1982), Wittgenstein on Rules and Private Language, Cambridge: Harvard University Press.

Miller, A. (2019), "Rule-following, Meaning, and Primitive Normativity," Mind 128 (511): 735760 .

Rump, J. (2018), "Making Sense of the Lived Body and the Lived World: Meaning and Presence in Husserl, Derrida and Noë," Continental Philosophy Review 51 (2): 141-67.

Wittgenstein, L. (1993), Philosophical Occasions, 1912-1951, eds. J. C. Klagge and A. Nordmann, Indianapolis: Hackett. . (2009), Philosophical Investigations, $4^{\text {th }}$ Ed., trans. G. E. M. Anscombe, P. M. S. Hacker, and J. Schulte, revised fourth edition by P. M. S. Hacker and J. Schulte, Oxford: WileyBlackwell. 
Rump, Husserlian Phenomenology, Rule-following, and Primitive Normativity 26 